\title{
Comorbidities and Negative Prognostic Factors in Lebanese Patients Presenting with Acute Decompensated Heart Failure with Preserved Ejection Fraction: A Multicenter Retrospective Study
}

\author{
Joseph El Khoury ${ }^{1}$, Ronza Bachnak ${ }^{2}$ Hiba El Assaad ${ }^{3}$, Nahed Damaj $^{4}$, Jad J Terro ${ }^{5}$ \\ ${ }^{1}$ Department of Cardiology, Middle East Institute of Health (MEIH), Bsalim, Lebanon \\ ${ }^{2}$ Department of Obstetrics and Gynecology, Faculty of Medical Sciences, Lebanese University, Beirut, Lebanon \\ ${ }^{3}$ Department of Head and Neck Surgery, Faculty of Medical Sciences, Lebanese University, Beirut, Lebanon \\ ${ }^{4}$ Faculty of Medical Sciences, Beirut, Lebanese University, Beirut, Lebanon \\ ${ }^{5}$ Department of General Surgery, Faculty of Medical Sciences, Lebanese University, Beirut, Lebanon
}

Corresponding Author: Jad J Terro, Beirut, Lebanon, j.terro@hotmail.com

Financial support: None

Conflict of Interest: None

Consent: Written consent was taken from the participants for the publication of this study

\section{Abstract}

Background: Congestive heart failure is responsible for repeated hospital admissions. It is classified into three types: (1) Heart Failure with reduced ejection fraction, (2) Heart failure with mid-range ejection fraction, and (3) Heart failure with preserved ejection fraction (HFpEF). It is essential to describe the risk factors of HFpEF patients' profiles as targeting them is crucial for management.

Aim: Our retrospective study aims to identify the clinical and echocardiographic characteristics associated with HFpEF and its mortality among hospitalized patients with acute decompensated heart failure.

Methods: 390 patients of all age groups presenting with acute heart failure decompensation at Mount Lebanon Hospital (MLH) and Middle East Institute of Health (MEIH, Bsalim) were recruited retrospectively between January 2014 and December 2016. We included 133 cases of HFpEF and collected data on each case including: baseline characteristics and comorbidities, electrocardiograms, laboratory studies, and echocardiographic parameters.

Results: The 133 Lebanese patients having HFpEF were elderly (76 \pm 10 years), with predominantly female gender (56\%). Hypertension (87.96\%) and diabetes $(53.38 \%)$ were the most frequently reported comorbidities. The overall in-hospital mortality was 4.5\%. Data was compared between living and deceased patients and the frequency of valvular heart disease $(p=0.005)$ and chronic kidney disease $(p=0.018)$ was significantly higher among deceased patients. Right ventricular (RV) dilation on echocardiography was significantly correlated with mortality. Elevated troponin, increased creatinine, hypochloremia, hyponatremia, and anemia were all lab markers associated with increased mortality $(p<0.05)$. 
Conclusion: Patients with HFpEF represent $43.5 \%$ of all decompensated HF cases, with chronic kidney disease, valvular heart diseases, anemia and troponinemia, being the predominant risk factors for adverse clinical outcomes. HFpEF remains an enormous burden on cardiologists for appropriate evaluation, triage, and management.

Keywords: Heart failure, heart failure preserved ejection fraction, HFpEF, acute decompensated heart failure, mortality, Lebanon

Abbreviations: BMI: Body Mass Index; BNP: Brain Natriuretic Peptide; CAD: Coronary Artery Disease; CHF: Congestive Heart Failure; CKD: Chronic Kidney Disease; COPD: Chronic Obstructive Pulmonary Disease; DD: Diastolic Dysfunction; DHF: Diastolic Heart Failure; DM: Diabetes Mellitus; HF: Heart Failure; HFpEF: Heart Failure with preserved Ejection Fraction; HErEF: Heart Failure with reduced Ejection Fraction; HFmrEF: Heart Failure with midrange Ejection Fraction; HTN: Hypertension; ICD-10: International Classification of Diseases,Tenth Revision; LA: Left Atrium; LV: Left Ventricle; LVEF: Left Ventricular Ejection Fraction; PAH: Pulmonary Artery Hypertension; SDH: Systo-diatolic HTN; TTE: Transthoracic Echocardiogram; VHD: Valvular Heart Disease.

\section{Introduction}

Congestive heart failure (CHF) is a pathophysiological state that results in the heart's inability to pump sufficient blood to meet the organism's metabolic demands [1]. The prevalence of Heart Failure (HF) has increased all over the world, with 23 million cases of HF reported worldwide and 6.2 million in the United States in the year of 2020 [2]. There was also an increase in the rate of hospitalization of HF patients. The prevalence increases with age, equally in both males and females [2].

HF is classified into three types: (1) heart failure with reduced ejection fraction (HFrEF, EF: $<40 \%$ ), (2) heart failure with preserved ejection fraction (HFpEF, $E F \geq 50 \%$ ), and heart failure with mid-range ejection fraction (HFmrEF, EF: 40$49 \%)$. Among all patients with HF, 40- $60 \%$ of them have a normal or near-normal Left Ventricular Ejection Fraction (LVEF) [3].

Diastolic dysfunction (DD) is a condition of impaired myocardial relaxation. It does not necessarily mean that HF is present. DD is not unique to diastolic HF, though it is nearly universal in HFrEF [4]. HFpEF is a cardiologic syndrome composed of diastolic heart failure (DHF), VHD, pericardial diseases, and right heart failure. DHF patients have HF signs and symptoms with a normal or slightly abnormal LVEF and LV volume, as well as abnormal LV filling and elevated filling pressures [5]. Echocardiography is the most used diagnostic test and is the gold standard. Diastolic stress testing, which is done by exercise echocardiography, is used to diagnose the early stages of HFpEF, where patients seem asymptomatic at rest but present with dyspnea at exertion [4]. One-third of HF patients have the diastolic type, and HFpEF is more prevalent among females [3]. Patients with advanced DD have structural heart abnormalities that increase the risk of other cardiovascular events and lead to a lower quality of life even in those that lack pertinent symptoms. Patients with DD have an 8 to 10 times higher risk of death within 5 years than patients with normal filling [6]. Patients with normal LVEF and elevated pulmonary artery systolic pressure (PASP) are considered as HFpEF until proven otherwise, especially because HFpEF is more prevalent than pulmonary artery hypertension (PAH) [4]. In one report by Lam et al., pulmonary hypertension, defined as PASP $>35 \mathrm{mmHg}$, was the only echocardiographic parameter associated with mortality in HFpEF [5].

In contrast to HFrEF, there is still a lack of knowledge of the exact pathophysiology of HfpEF, its risk factors and the effective medical treatments to improve quality of life [7]. Comorbidities such as hypertension (HTN), Diabetes Mellitus (DM), and dyslipidemia (DL) adversely affect HFpEF, and thus the aggressive control of such diseases improves the overall outcomes [4]. HF patients usually have several comorbid illnesses that adversely influence quality of life. DM, HTN, Obesity (elevated Body Mass Index, BMI), chronic obstructive pulmonary disease (COPD), chronic kidney disease (CKD), coronary artery disease (CAD), and anemia are the most prevalent and reported comorbidities. Electrolyte disturbances have been a subject of interest in HF patients, where data has shown that hypochloremia and hyponatremia were associated with higher morbidity and mortality 
[7]. A similar association was seen with high serum Troponin level.

In light of the complex risk factor profile of patients with HFpEF and the absence of evidence-based, effective therapy for HFpEF, it is crucial to accurately characterize the comorbidities associated with HFpEF and its outcomes in specific populations in order to target them. Therefore, we conducted a retrospective study to provide a detailed clinical assessment of patients with HFpEF hospitalized for acute decompensated heart failure. The study involved two big centers in Lebanon, Mount Lebanon Hospital (MLH) and Middle East Institute of Health (MEIH), between the 1st of January 2014 and the 31st of December 2016.

\section{Methods}

\section{a) Study Participants}

We conducted a retrospective study, including Lebanese patients of all age groups with symptoms related to HF. ICD- 10 Codes of acutely decompensated heart failure were registered by the Mount Lebanon Hospital (MLH) and Middle East Institute of Health (MEIH) between the 1st of January 2014 and the 31st of December 2016 and were used for the selection of cases. In total, we reviewed 390 medical records.

The following were the inclusion criteria: Lebanese patients from all age groups admitted to the hospital with at least one symptom related to HF and having the "acutely decompensated HF ICD-10 code" mentioned on their discharge sheet. Exclusion criteria: Patients who had TTE results showing $E F<50 \%$, those with current preserved EF $(>50 \%)$ but having a history of reduced $\mathrm{EF}(<50 \%) ;$ and patients having disorders known to be associated with diastolic dysfunction such as infiltrative heart disease, hypertrophic cardiomyopathy, restrictive cardiomyopathy, cor pulmonale, constrictive pericarditis, severe stenosis of the mitral valve or valvular lesions such as acute failure of the mitral valve that necessitated an urgent open-heart procedure. The study included 133 patients, and there was a two-year follow up.

\section{b) Ethical Considerations}

All medical charts were de-identified. Patients' anonymity and confidentiality were maintained throughout the study. IRB approval was obtained from both hospital centers.

\section{c) Data collection}

We retrieved the following data from the medical charts of the patients selected for the study: (1) Clinical determinants of HF (dyspnea, orthopnea, LLE, JVD), (2) Chest X-ray findings (lung congestion, cardiomegaly), (3) ECG analysis (ischemic changes, atrial fibrillation), (4) TTE findings done within 48-72 hours of admission (EF, DD grade, LVH [defined as interventricular septal thickness and posterior wall thickness $\geq 12 \mathrm{~mm}$ ] [8], left atrium dilatation [LA volume index $>35 \mathrm{~mL} / \mathrm{m} 2$ ], elevated PASP [ $>35 \mathrm{mmHg}$ ], right heart dilatation [RV base $42 \mathrm{~mm}$ and $\mathrm{RV}$ mid cavity >35mm]) [9]. Comorbidities (smoking, HTN, DM, DL, COPD, CKD, anemia, VHD, pulmonary hypertension [defined as PASP > 35 $\mathrm{mmHg}]$ ), age, sex, and BMI were all collected and tabulated from the patients' medical files at both hospitals. Furthermore, laboratory studies collected during the first 24-48 hours of admission included hemoglobin, hematocrit, $\mathrm{Na}^{+}, \mathrm{K}^{+}, \mathrm{Cl}^{-}$, Creatinine, BUN and Troponin I. We retrieved such data from the patients' medical charts. Cases with high WBC (> $\left.12 \times 10^{9} / \mathrm{L}\right)$, increased CRP ( $>5 \mathrm{mg} / \mathrm{L})$, elevated creatinine (> $1 \mathrm{mg} / \mathrm{dL})$, low $\mathrm{Na}^{+}(\leq 135 \mathrm{mEq} / \mathrm{L})$, low $\mathrm{K}^{+}(<3.5$ $\mathrm{mEq} / \mathrm{L})$, low $\mathrm{Cl}^{-}$( $\left.\leq 96 \mathrm{mEq} / \mathrm{L}\right)$, and low hemoglobin $(<12 \mathrm{~g} / \mathrm{dL}$ in females, and $<13 \mathrm{~g} / \mathrm{dL}$ in males) were all noted. We also recorded the number of admissions with elevated troponin I (> $0.1 \mathrm{ng} / \mathrm{mL})$.

\section{d) Statistical Analysis}

Analyses for the cross-sectional study was performed for all variables. Continuous variables were noted as mean values and standard deviations, and number and percentage for categorical variables. All analyses were twosided, and significance was judged at $p<0.05$ with corresponding Confidence Intervals (Cls) of $95 \%$.

The primary study outcome was in-hospital mortality. Differences in the distribution of patients' signs, symptoms, laboratory and imaging findings, and echocardiography data were compared using Pearson's Chi-square test for categorical variables and t-test for normally distributed continuous variables according to the patients' survival status. Analyses were done 
Table 1. Sample t-test were used to compare the mean age and BMI between deceased and alive HFpEF patients, whereas a Chi-square was used for the remaining dichotomous categorical characteristics.

\begin{tabular}{|l|l|l|l|l|}
\hline \multicolumn{1}{|c|}{ Patient characteristics } & All Patients $(\mathrm{n}=133)$ & \multicolumn{1}{|c|}{ Alive (n=127) } & Deceased (6) & p-value \\
\hline Age, mean (SD) & $76(10)$ & $76(10)$ & $74(9)$ & 0.653 \\
\hline Male gender, $\mathrm{n}(\%)$ & $58 / 133(43.6 \%)$ & $55 / 127(43.3 \%)$ & $3 / 6(50 \%)$ & 0.747 \\
\hline Smoking history & $58 / 133(43.6 \%)$ & $56 / 127(44.1 \%)$ & $2 / 6(33.33 \%)$ & 0.603 \\
\hline Dyslipidemia, $n(\%)$ & $63 / 133(47.3 \%)$ & $61 / 127(48 \%)$ & $2 / 6(33.33 \%)$ & 0.481 \\
\hline Hypertension, $\mathrm{n}(\%)$ & $117 / 133(87.9 \%)$ & $113 / 127(89 \%)$ & $4 / 6(66.67 \%)$ & 0.101 \\
\hline Coronary artery disease, $\mathrm{n}(\%)$ & $43 / 133(32.2 \%)$ & $42 / 127(33.07 \%)$ & $1 / 6(1.167 \%)$ & 0.226 \\
\hline Chronic kidney disease, $\mathrm{n}(\%)$ & $34 / 133(25.5 \%)$ & $30 / 127(23.62 \%)$ & $4 / 6(66.67 \%)$ & $0.018^{*}$ \\
\hline Chronic obstructive lung disease, $\mathrm{n}(\%)$ & $28 / 133(21 \%)$ & $26 / 127(20.5 \%)$ & $2 / 6(33.33 \%)$ & 0.45 \\
\hline Diabetes mellitus, $\mathrm{n}(\%)$ & $71 / 133(53.3 \%)$ & $68 / 127(53.5 \%)$ & $3 / 6(50 \%)$ & 0.865 \\
\hline Valvulopathy, $\mathrm{n}(\%)$ & $28 / 133(21 \%)$ & $24 / 127(18.9 \%)$ & $4 / 6(66.7 \%)$ & $0.005^{*}$ \\
\hline Mean BMl (SD) & $29.13(5.4)$ & $29.5(5.2)$ & $22.22(3.91)$ & $0.003^{*}$ \\
\hline
\end{tabular}

using the Statistical Package of Social Science (IBM SPSS, version 22).

\section{Results}

Out of a total of 390 medical files of Lebanese patients admitted for acutely decompensated heart failure from two medical centers in Lebanon (MEIH and MLH) between the $1^{\text {st }}$ of January 2014 and $31^{\text {st }}$ of December 2016, 133 cases had HFpEF (49\%). The rest of the subjects were 216 cases of HFrEF, 39 cases of HFmrEF, 1 case of constrictive pericarditis, and 1 case of severe mitral stenosis; these subjects were excluded from our study (Fig. 1).

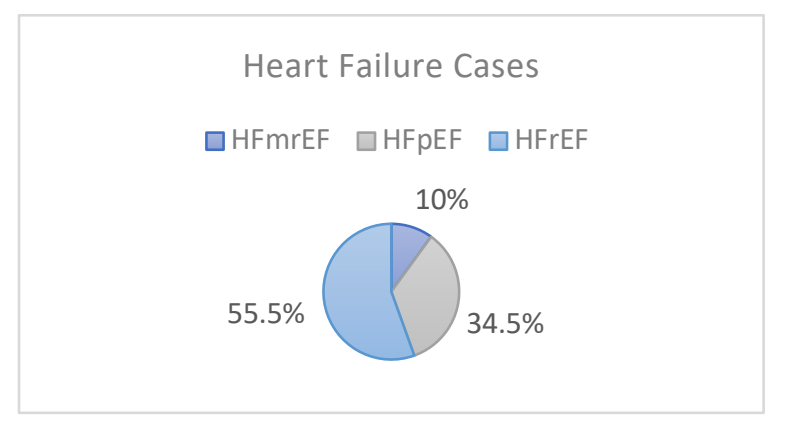

Figure 1: Prevalence of different subtypes of HF among patients hospitalized for acute decompensated heart failure in 2 medical centers in Lebanon, admitted between January 2014 and December 2016

Of the 133 cases of HFpEF, 75 patients were females $(56.4 \%), 6$ died during their hospital admission (4.5\%), and the mean age was 76+/10 years. Further, $37.1 \%$ of the population had a $\mathrm{BMI}$ in the overweight category (Fig. 2).

Figure 3 outlines the major demographic, social characteristics, and comorbidities in survived and deceased patients with HFpEF. Hypertension and diabetes mellitus were the most commonly reported comorbidities, encountered in $87.7 \%$ and $53.38 \%$ of HFpEF patients, respectively. However, only chronic kidney disease and valvular heart disease were significantly more prevalent in deceased HFpEF patients $(66.67 \%$ vs. $23.63 \%, p=0.018)$ (Table 1).

Upon presentation, the most common findings in patients with HFpEF were: Dyspnea $(91 \%$, 121/133), vascular congestion (78.94\%, $105 / 133)$ and cardiomegaly on CXR (60.9\%, 81/133). We outlined the other findings in Table 2. However, there was no statistical difference in the presentation findings between HFpEF patients who had survived and those who had passed away at the end of the two-year followup (Table 2).

Regarding echocardiographic parameters, left atrial dilation and left ventricular hypertrophy were prevalent among HFpEF patients and were observed in $62 \%$ and $61 \%$ of patients, respectively. However, only right ventricular 
Table 2. Prevalence of several clinical and imaging characteristics among patients with HFpEF

\begin{tabular}{|l|l|l|l|l|}
\hline & All Patients $(\mathrm{n}=133)$ & Alive $(\mathrm{n}=127)$ & Dead $(\mathrm{n}=6)$ & $p$-value \\
\hline Dyspnea & $121 / 133(91 \%)$ & $115 / 127(90.5 \%)$ & $6 / 6(100 \%)$ & 0.43 \\
\hline LLE & $45 / 133(33.8 \%)$ & $43 / 127(33.8 \%)$ & $3 / 6(50 \%)$ & 0.553 \\
\hline Orthopnea & $14 / 133(10.5 \%)$ & $13 / 127(10.2 \%)$ & $1 / 6(16.67 \%)$ & 0.616 \\
\hline Crackling & $75 / 133(56.4 \%)$ & $71 / 127(55.9 \%)$ & $4 / 6(33.33 \%)$ & 0.603 \\
\hline Lung congestion on CXR & $105 / 133(78.9 \%)$ & $99 / 127(77.9 \%)$ & $6 / 6(100 \%)$ & 0.196 \\
\hline Cardiomegaly on CXR & $81 / 133(60.9 \%)$ & $77 / 127(60.63 \%)$ & $4 / 6(50 \%)$ & 0.767 \\
\hline Atrial fibrillation on ECG & $19 / 133(14.3 \%)$ & $17 / 127(13.38 \%)$ & $2 / 6(33.33 \%)$ & 0.172 \\
\hline Ischemic changes on ECG & $5 / 133(3.7 \%)$ & $5 / 127(3.9 \%)$ & $0 / 6(0 \%)$ & 0.620 \\
\hline
\end{tabular}

Table 3. Prevalence of several echocardiographic parameters among patients with HFpEF

\begin{tabular}{|l|l|l|l|l|}
\hline & All Patients $(\mathrm{n}=133)$ & Alive $(\mathrm{n}=127)$ & Dead (6) & $p^{-v a l u e}$ * \\
\hline High PASP $(>35 \mathrm{mmHg})$ & $61 / 133(45.8 \%)$ & $58 / 127(45.6 \%)$ & $3 / 6(50 \%)$ & 0.835 \\
\hline RV dilation & $25 / 133(18.79 \%)$ & $22 / 127(17.3 \%)$ & $3 / 6(50 \%)$ & 0.045 \\
\hline LA dilation & $83 / 133(62.4 \%)$ & $79 / 127(62.2 \%)$ & $4 / 6(33.3 \%)$ & 0.825 \\
\hline LVH & $82 / 133(61.65 \%)$ & $78 / 127(61.4 \%)$ & $4 / 6(33.3 \%)$ & 0.796 \\
\hline EF (\%), mean (SD) & $58.44(7.77)$ & $58.5(7)$ & $57.1(5)$ & 0.381 \\
\hline
\end{tabular}

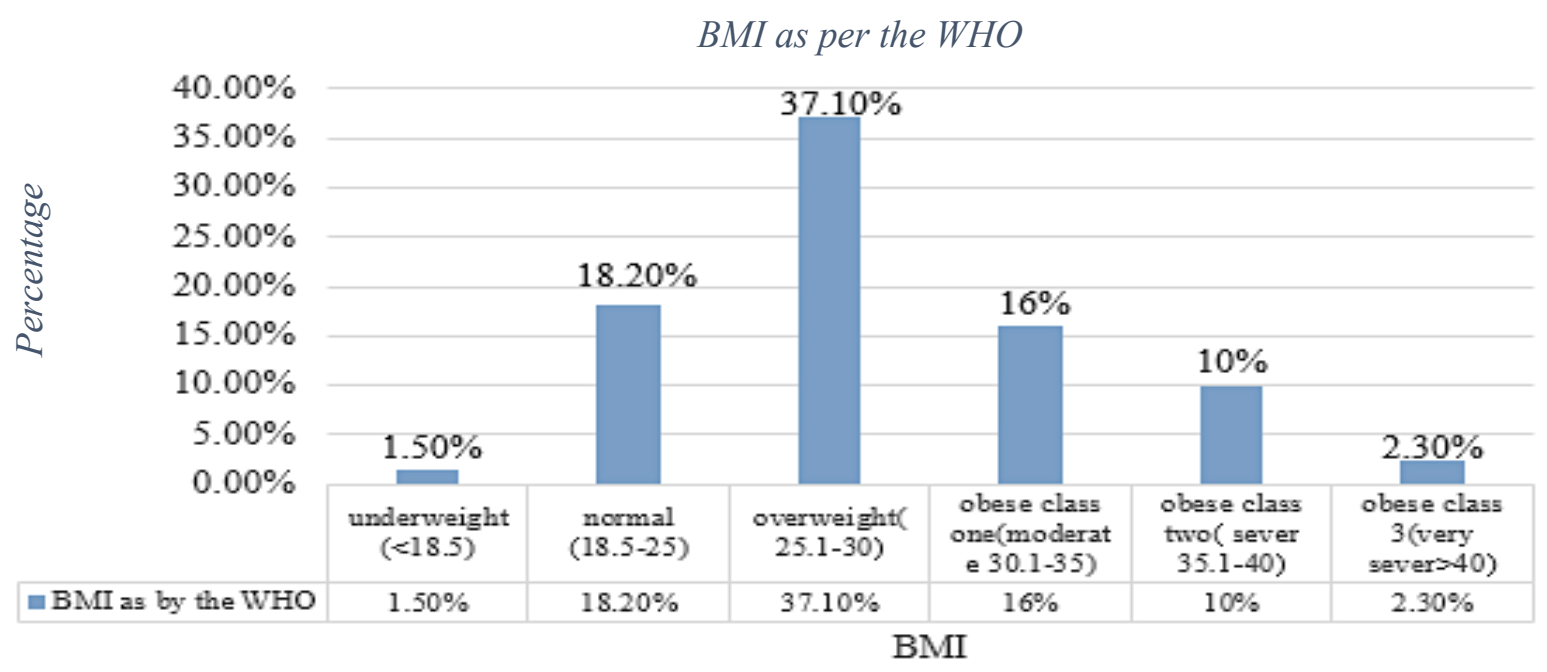

Figure 2. Percentage of HFpEF cases falling into the 6 categories of BMI as listed by the WHO 
Table 4: Chi-square was used for the high troponin, anemia, hypochloremia and natremia while sample t test was used to compare else variables.

\begin{tabular}{|c|c|c|c|c|}
\hline & All Patients $(n=133)$ & Alive $(n=127)$ & Dead (6) & $p$-value \\
\hline $\mathrm{Na}(\mathrm{mEq} / \mathrm{L})$, mean (SD) & $137.4(4.46)$ & $137(4)$ & $136(5)$ & 0.616 \\
\hline $\mathrm{K}(\mathrm{mEq} / \mathrm{L})$, mean $(\mathrm{SD})$ & $4.5(2.94)$ & $4.59(3)$ & $4(0.6)$ & 0.629 \\
\hline $\mathrm{Cl}(\mathrm{mEq} / \mathrm{L})$, mean (SD) & $98.94(5.5)$ & $99(5.4)$ & $97.33(6.94)$ & 0.466 \\
\hline $\mathrm{Cr}(\mathrm{mg} / \mathrm{dL})$, mean (SD) & $1.85(1.74)$ & $1.84(1.76)$ & $2.23(1.16)$ & 0.593 \\
\hline BUN (mg/dL), mean (SD) & $39.43(29.41)$ & $38.65(28.41)$ & $55.83(46.55)$ & 0.163 \\
\hline $\begin{array}{l}\text { Troponin I level in } \mathrm{ng} / \mathrm{ml} \text {, mean } \\
\text { (SD) }\end{array}$ & $0.061(0.16)$ & $0.046(0.075)$ & $0.381(0.66)$ & $<0.0001^{*}$ \\
\hline Hemoglobin, mean (SD) & $11.41(2.24)$ & $11.48(2.23)$ & $9.8(1.77)$ & 0.087 \\
\hline High troponin, $\mathrm{n}(\%)$ & $24 / 133(18 \%)$ & 21/127 (16.5 \%) & $3 / 6(50 \%)$ & $<0.0001^{*}$ \\
\hline High creatinine, $\mathrm{n}(\%)$ & $83 / 133(62.4 \%)$ & 78/127 (61.4 \%) & $5 / 6(83.3 \%)$ & $0.001^{*}$ \\
\hline Hyponatremia, n (\%) & 26/133 (19.5\%) & $23 / 127(18.11 \%)$ & $3 / 6(33.3 \%)$ & 0.16 \\
\hline Hypochloremia, n (\%) & $53 / 133(39.8 \%)$ & 49/127 (38.6 \%) & $4 / 6(66.7 \%)$ & $<0.0001^{*}$ \\
\hline Anemia, $\mathrm{n}(\%)$ & $81 / 133(60.9 \%)$ & $76 / 127(60 \%)$ & $5 / 6(83.3 \%)$ & $<0.0001^{*}$ \\
\hline
\end{tabular}

\section{Age Groups}

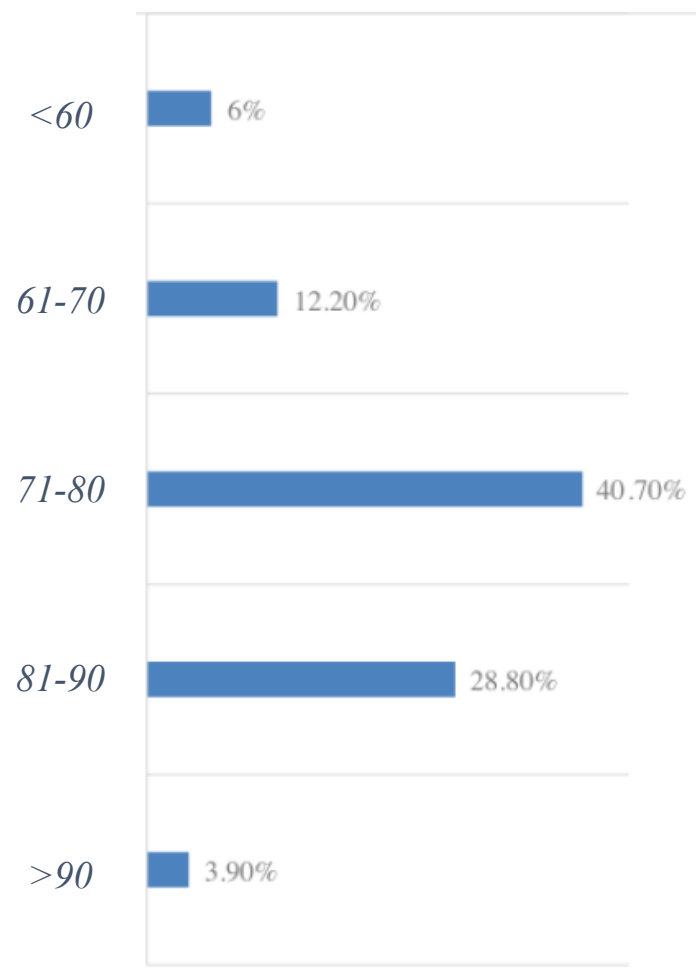

Figure 3. Percentage of HFpEF patients falling into 5 ages groups

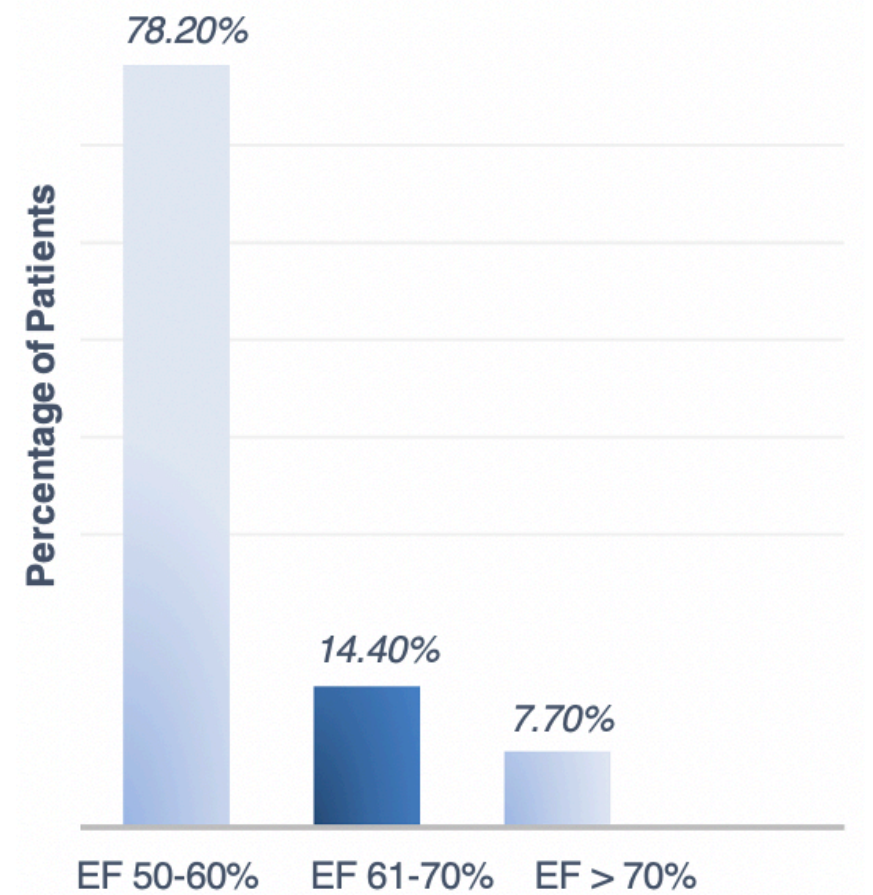

Figure 4. Percentage of patients having EF \% falling within 3 separate ranges, $50-60 \%, 61-70 \%$ and $>70 \%$ 
dilation was statistically more prevalent in deceased patients. (50\% vs. $17.32 \%, p=0.045$, respectively) (Table 3).

Although the mean sodium, potassium, chloride, creatine, hemoglobin, and BUN levels were not statistically different between survived and deceased HFpEF patients, anemia and hypochloremia were more prevalent in deceased individuals $(83.3 \%$ vs. $59.8 \%$; $66.67 \%$ vs $38.58 \%$; respectively, $p<0.0001)$. High creatinine was also more prevalent among HFpEF patients who passed away, and the mean troponin level was almost 9-folds higher in the deceased group $(0.381 \pm 0.66$ vs. $0.046 \pm 0.075, p<0.0001)$ (Table 4).

Table 4 shows that high troponin, high creatinine, low chloride, and anemia were correlated with mortality. In addition, elevated troponin, increased creatinine, anemia, low chloride, and low sodium in serum are associated significantly with hospital readmission $(p<0.05)$.

\section{Discussion}

In this study, we aimed to provide a detailed risk factor profile and describe the signs, symptoms, and imaging findings of patients with HFpEF. We also aimed to report on their clinical outcomes following hospital admission with acute decompensated heart failure. This is the first study of its kind done on a multicenter cohort of Lebanese patients.

The results of this study are compatible with previous studies such as the Karolinska Rennes (KaRen) study and the Prevention of Renal and Vascular End-stage Disease (PREVEND) study. The KaRen study is a prospective observational study done to characterize heart failure patients with preserved ejection fraction (HFpEF) and to identify prognostic factors for long-term mortality and morbidity. The study looked at a French and Swedish sample of 539 patients between 2007 and 2011 [32]. The PREVEND study is a community-based, middle-aged 11-year cohort study in the Netherlands. It recruited 8592 subjects to study the predictive value of risk factors and established cardiovascular biomarkers on new-onset HFrEF vs. HFpEF [33].

HFpEF represents $40 \%$ of cases of HF and is more prevalent and severe in females. Its pathophysiology is ill-defined compared to HFrEF, but both types are serious conditions with similar outcomes profile [3]. There are several risk factors of HFpEF reported in the literature. DM is a well-known indolent factor in HF pathogenesis and myocardial diseases and is associated with a worse prognosis, more frequent hospital admissions, and greater HF severity. It is associated with an increased rate of HF in both males and females. Still, the severity and frequency of cardiovascular complications proved to be gender-related (occurring in females more than in males) [10]. Hypertension is an important factor that leads to HF if not controlled early. It yields a mixture of LV remodeling, myocardial fibrosis of variable degrees, and LV DD. HF patients with HTN have an increased risk of hospitalization due to HF decompensation, with a notable increase in total mortality rates. Therefore, prompt and precise management for hypertension must be implemented [11]. In this study, HTN and DM were very prevalent but not associated with mortality among HFpEF patients.

The distribution of age and gender in this population (high mean age and predominantly female population) is very similar to what is reported in the literature. Because gender affects cardiac remodeling, the LV tends to hypertrophy more and dilate less in women than in men when exposed to high overload pressure [31]. In our study, CKD was more prevalent among deceased patients with HFpEF. CKD was found in $25.26 \%$ of our HFpEF patients, which is less than what was noted in a Northwestern University study (48\%) [37]. CKD was still a significant death predictor $(\mathrm{p}=0.018)$, as was reported in the Northwestern study [37]. CKD leads to derangements in vascular physiology which in turn yield a bad cardiovascular outcome through abnormal coagulation and fibrinolytic systems, dysfunction of the endothelium, loss of balance between endothelin and nitrogen oxide, electrolyte disturbances that can lead to arrhythmia, and over activation of the sympathetic nervous system and reninangiotensin-aldosterone systems [17]. Furthermore, VHD was noted in $21 \%$ of cases and was associated with mortality among the study patients, which is concordant with results from other studies showing a prevalence of $8 \%$ [35], and $13 \%$ [36].

Electrolyte disturbances have been and remain a subject of interest in patients with HFpEF. 
Hyponatremia is a known predictor of poor outcomes in HF patients. [21]. The KorAHF analysis showed that hyponatremic patients have increased in-hospital mortality rates [22]. This was also supported by the Beta-Blocker Evaluation of Survival (BEST) trial, which showed that hyponatremia and hypochloremia were associated with more significant morbidity and mortality, although serum chloride remained the strongest predictor of mortality [23]. This study found that the prevalence of hospital death was higher in HFpEF patients with high troponin level, elevated creatinine level, hypochloremia, hyponatremia, and anemia. Our findings are concordant with those reported in the KaRen study and the BEST trial [32], where hyponatremia and hypochloremia were found to be markers of worse prognosis, respectively. Moreover, a prospective study by Douglas et al. on 363 patients hospitalized for decomposed HFpEF reported an elevated troponin level to be associated with short, intermediate, and longterm mortality [38].

CAD is associated with augmented risk of HFpEF and induces DD by two primary mechanisms: (1) impairment of energy-dependent active relaxation by ischemia and (2) alteration of passive relaxation due to fibrosis. DD also leads to myocardial ischemia by interfering with diastolic coronary filling [4]. HFpEF patients with CAD proven by angiography had a more significant decrease in ejection fraction and increased mortality than HFpEF patients without CAD [18]. Thus, identification of CAD is systematically performed in HFpEF patients using coronary angiography unless contraindicated. Also, revascularization can lead to cardiac function preservation and better outcomes [4]. This is evident in our study, as elevated troponin levels have been identified in patients with HFpEF. Potential contributing mechanisms include subendocardial ischemia, inflammatory cytokine activation, and increased wall stress leading to myocyte necrosis with troponin release [24]. High troponin was related to higher in-hospital death and greater length of stay independently of other risk factors [25].

In terms of echocardiogram parameters, most of our patients had LA dilation (62.24\%) and LVH $(61.65 \%)$, while the only parameter found to be a predictor of worse prognosis and death was RV dilation $(p=0.045)$. This is in agreement with a community-based study done in 2014 [33]. Global longitudinal strain (GLS), a parameter measured through 2-dimensional speckle tracking echocardiography, has become a novel sensitive tool for assessing left ventricular (LV) function. GLS is increased with LV dysfunction, while traditional markers may be normal. It is an incredible prognostic factor and useful for predicting any future deterioration or $\mathrm{HF}$ decompensations. This prediction was found to be more useful in males rather than females [39, 40].

This study has several limitations. It included HFpEF cases from 2 centers in Lebanon, with only 6 deaths reported, which may affect prognostic mortality factors. We retrieved data retrospectively from the residents' and physicians' notes and ICD10 codes. Some information was absent from the charts. Therefore only 33 patients were reported to have DD.

Moreover, although it would have been informative, the GLS is not routinely measured and reported by Lebanese cardiologists. More laboratory variables were intended to be included (i.e., pro-BNP, thyroid function tests, Calcium levels, $\mathrm{HbA} 1 \mathrm{C}$, uric acid, and lipid profiles), but this data was often not present in the charts as well. Finally, the analyses are only descriptive, and any correlations cannot be interpreted as causal relationships.

\section{Conclusion}

In conclusion, HFpEF remains a challenging diagnosis after excluding all non-cardiac causes for heart failure. We have shed light on the essential comorbidities, paraclinical findings, and echocardiographic characteristics associated with increased HFpEF patient mortality. Carefully and thoroughly analyzing these findings may help physicians assess and treat each HFpEF patient. However, drawing a definite conclusion and establishing a proper HFpEF treatment paradigm will require more extensive, multi-centric, prospective trials.

\section{References}

1. Braunwald E. Heart failure. JACC Heart Fail. 2013 Feb;1(1):1-20. doi: 10.1016/j.jchf.2012.10.002. Epub 2013 Feb 4. PMID: 24621794. https://doi.org/10.1016/j.jchf.2012.10.002 
2. Virani SS, Alonso A, Benjamin EJ, et al. Heart Disease and Stroke Statistics-2020 Update: A Report From the American Heart Association. Circulation. 2020 Mar 3;141(9):e139-e596. doi: 10.1161/CIR.0000000000000757. Epub 2020 Jan 29. PMID: 31992061. https://doi.org/10.1161/CIR.0000000000000757

3. Ponikowski P, Voors AA, Anker SD, et al. 2016 ESC Guidelines for the diagnosis and treatment of acute and chronic heart failure: The Task Force for the diagnosis and treatment of acute and chronic heart failure of the European Society of Cardiology (ESC)Developed with the special contribution of the Heart Failure Association (HFA) of the ESC. Eur Heart J. 2016 Jul 14;37(27):2129-2200. doi: 10.1093/eurheartj/ehw128. Epub 2016 May 20. Erratum in: Eur Heart J. 2016 Dec 30;: PMID: 27206819.

4. Oktay AA, Shah SJ. Diagnosis and management of heart failure with preserved ejection fraction: 10 key lessons. Curr Cardiol Rev. 2015;11(1):42-52. doi: 10.2174/1573403x09666131117131217. PMID: 24251461; PMCID: PMC4347209. https://doi.org/10.2174/1573403X096661311171312 17

5. Lam CSP, Voors AA, de Boer RA, Solomon SD, van Veldhuisen DJ. Heart failure with preserved ejection fraction: from mechanisms to therapies. Eur Heart J. 2018 Aug 7;39(30):2780-2792. doi: 10.1093/eurheartj/ehy301. Erratum in: Eur Heart J. 2019 Feb 7;40(6):528. PMID: 29905796. https://doi.org/10.1093/eurheartj/ehy301

6. Abhayaratna WP, Marwick TH, Smith WT, Becker NG. Characteristics of left ventricular diastolic dysfunction in the community: an echocardiographic survey. Heart. 2006 Sep;92(9):1259-64. doi: 10.1136/hrt.2005.080150. Epub 2006 Feb 17. PMID: 16488928; PMCID: PMC1861192. https://doi.org/10.1136/hrt.2005.080150

7. Testani JM, Hanberg JS, Arroyo JP, et al. Hypochloraemia is strongly and independently associated with mortality in patients with chronic heart failure. Eur J Heart Fail. 2016 Jun;18(6):660-8. doi: 10.1002/ejhf.477. Epub 2016 Jan 13. PMID: 26763893; PMCID: PMC5471359. https://doi.org/10.1002/ejhf.477

8. McFarland TM, Alam M, Goldstein S, et al. Echocardiographic diagnosis of left ventricular hypertrophy. Circulation. 1978 Jun;57(6):1140-4. doi: 10.1161/01.cir.57.6.1140. PMID: 147758. https://doi.org/10.1161/01.CIR.57.6.1140

9. Kossaify A. Echocardiographic Assessment of the Right Ventricle, from the Conventional Approach to Speckle Tracking and Three-Dimensional Imaging, and Insights into the "Right Way" to Explore the
Forgotten Chamber. Clin Med Insights Cardiol. 2015 Jul 5;9:65-75. doi: 10.4137/CMC.S27462. PMID: 26244034; PMCID: PMC4493918. https://doi.org/10.4137/CMC.S27462

10. Palau P, Bertomeu-González V, Sanchis J, et al. Differential prognostic impact of type 2 diabetes mellitus in women and men with heart failure with preserved ejection fraction. Rev Esp Cardiol (Engl Ed). 2020 Jun;73(6):463-470. English, Spanish. doi: 10.1016/j.rec.2019.09.002. Epub 2019 Oct 17. PMID: 31629690. https://doi.org/10.1016/j.rec.2019.09.002

11. Mottram PM, Haluska B, Leano R, et al. Effect of aldosterone antagonism on myocardial dysfunction in hypertensive patients with diastolic heart failure. Circulation. 2004 Aug 3;110(5):558-65. doi: 10.1161/01.CIR.0000138680.89536.A9. Epub 2004 Jul 26. PMID: 15277317. https://doi.org/10.1161/01.CIR.0000138680.89536.A 9

12. Wong CY, O'Moore-Sullivan T, Leano R, et al. Alterations of left ventricular myocardial characteristics associated with obesity. Circulation. 2004 Nov 9;110(19):3081-7. doi: 10.1161/01.CIR.0000147184.13872.0F. Epub 2004 Nov $1 . \quad$ PMID: 15520317. https://doi.org/10.1161/01.CIR.0000147184.13872.0 $\mathrm{F}$

13. Lee SL, Daimon M, Di Tullio MR, et al. Relationship of Left Ventricular Diastolic Function to Obesity and Overweight in a Japanese Population With Preserved Left Ventricular Ejection Fraction. Circ J. 2016 Aug 25;80(9):1951-6. doi: 10.1253/circj.CJ-16-0381. Epub 2016 Jul $7 . \quad$ PMID: 27385498. https://doi.org/10.1253/circj.CJ-16-0381

14. Kubota Y, Asai K, Murai K, et al. COPD advances in left ventricular diastolic dysfunction. Int $\mathrm{J}$ Chron Obstruct Pulmon Dis. 2016 Mar 29;11:649-55. doi: 10.2147/COPD.S101082. PMID: 27099482; PMCID: PMC4820215.

https://doi.org/10.2147/COPD.S101082

15. Fujimoto N, Okada Y, Shibata S, et al. Effects of sex and hypertension subtype on haemodynamics and left ventricular diastolic function in older patients with stage 1 hypertension. J Hypertens. 2013 Nov;31(11):2282-9; discussion 2289. doi: 10.1097/HJH.0b013e3283649730. PMID: 24077248; PMCID: PMC3864621. https://doi.org/10.1097/HJH.0b013e3283649730

16. Hawkins NM, Petrie MC, Jhund PS, et al. Heart failure and chronic obstructive pulmonary disease: diagnostic pitfalls and epidemiology. Eur J Heart Fail. 2009 Feb;11(2):130-9. doi: 10.1093/eurjhf/hfn013. PMID: 19168510; PMCID: PMC2639415. https://doi.org/10.1093/eurjhf/hfn013 
17. Levy D, Larson MG, Vasan RS, Kannel WB, Ho KK. The progression from hypertension to congestive heart failure. JAMA. 1996 May 22-29;275(20):1557-62. PMID: 8622246. https://doi.org/10.1001/jama.275.20.1557

18. McAlister FA, Ezekowitz J, Tonelli M, Armstrong PW. Renal insufficiency and heart failure: prognostic and therapeutic implications from a prospective cohort study. Circulation. 2004 Mar 2;109(8):1004-9. doi: 10.1161/01.CIR.0000116764.53225.A9. Epub 2004 Feb 9. PMID: 14769700. https://doi.org/10.1161/01.CIR.0000116764.53225.A 9

19. Hwang SJ, Melenovsky V, Borlaug BA. Implications of coronary artery disease in heart failure with preserved ejection fraction. J Am Coll Cardiol. 2014 Jul 1;63(25 Pt A):2817-27. doi: 10.1016/j.jacc.2014.03.034. Epub 2014 Apr 23. PMID: 24768876. https://doi.org/10.1016/j.jacc.2014.03.034

20. Tehrani F, Phan A, Morrissey R, Chien C, et al. The prognostic value of anemia in patients with diastolic heart failure. Tex Heart Inst J. 2009;36(3):220-5. PMID: 19568391; PMCID: PMC2696500.

21. Groenveld HF, Januzzi JL, Damman K, et al. Anemia and mortality in heart failure patients a systematic review and meta-analysis. J Am Coll Cardiol. 2008 Sep 2;52(10):818-27. doi: 10.1016/j.jacc.2008.04.061. PMID: 18755344. https://doi.org/10.1016/j.jacc.2008.04.061

22. Bavishi C, Ather S, Bambhroliya A, et al. Prognostic significance of hyponatremia among ambulatory patients with heart failure and preserved and reduced ejection fractions. Am J Cardiol. 2014 Jun 1;113(11):1834-8. doi: 10.1016/j.amjcard.2014.03.017. Epub 2014 Mar 18. PMID: 24837261 https://doi.org/10.1016/j.amjcard.2014.03.017

23. Park JJ, Cho YJ, Oh IY, et al. Short and long-term prognostic value of hyponatremia in heart failure with preserved ejection fraction versus reduced ejection fraction: An analysis of the Korean Acute Heart Failure registry. Int J Cardiol. 2017 Dec 1;248:239-245. doi: 10.1016/j.ijcard.2017.08.004. Epub 2017 Aug 5. PMID: 28821416.

https://doi.org/10.1016/j.ijcard.2017.08.004

24. Cuthbert JJ, Pellicori P, Rigby A, et al. Low serum chloride in patients with chronic heart failure: clinical associations and prognostic significance. Eur J Heart Fail. 2018 Oct;20(10):1426-1435. doi: 10.1002/ejhf.1247. Epub 2018 Jun 26. PMID: 29943886. https://doi.org/10.1002/ejhf.1247

25. Thawabi M, Hawatmeh A, Studyvin S, et al. Cardiac troponin and outcome in decompensated heart failure with preserved ejection fraction. Cardiovasc Diagn Ther. 2017 Aug;7(4):359-366. doi: 10.21037/cdt.2017.03.17. PMID: 28890872; PMCID: PMC5582062.

https://doi.org/10.21037/cdt.2017.03.17

26. Pandey A, Golwala $H$, Sheng $S$, et al. Factors Associated With and Prognostic Implications of Cardiac Troponin Elevation in Decompensated Heart Failure With Preserved Ejection Fraction: Findings From the American Heart Association Get With The Guidelines-Heart Failure Program. JAMA Cardiol. 2017 Feb 1;2(2):136-145. doi: 10.1001/jamacardio.2016.4726. PMID: 28030747. https://doi.org/10.1001/jamacardio.2016.4726

27. Froeschl M, Haddad H, Commons AS, Veinot JP. Thyrotoxicosis-an uncommon cause of heart failure. Cardiovasc Pathol. 2005 Jan-Feb;14(1):24-7. doi: 10.1016/j.carpath.2004.11.003. PMID: 15710288. https://doi.org/10.1016/j.carpath.2004.11.003

28. Abdollahi Moghadam A, Vakilian F, Shayesteh M. Relationship between heart failure with preserved ejection fraction and thyroid disorders: Review of the Literature. Reviews in Clinical Medicine. 2016 Feb 21.

29. Biondi B. Mechanisms in endocrinology: Heart failure and thyroid dysfunction. Eur J Endocrinol. 2012 Nov;167(5):609-18. doi: 10.1530/EJE-12-0627. Epub 2012 Sep 6. PMID: 22956554. https://doi.org/10.1530/EJE-12-0627

30. Masaki M, Komamura K, Goda A, et al. Elevated arterial stiffness and diastolic dysfunction in subclinical hypothyroidism. Circ J. 2014;78(6):1494500. doi: 10.1253/circj.cj-13-1556. Epub 2014 Apr 3. PMID: 24694766. https://doi.org/10.1253/circj.CJ-131556

31. Kinugasa Y, Yamamoto K. Subclinical hypothyroidism as a new therapeutic target for patients with heart failure with preserved ejection fraction. Circ J. 2014;78(6):1333-4. doi: 10.1253/circj.cj-14-0436. Epub 2014 Apr 24. PMID: 24758764. https://doi.org/10.1253/circj.CJ-14-0436

32. Donal E, Lund LH, Oger E, et al. Baseline characteristics of patients with heart failure and preserved ejection fraction included in the Karolinska Rennes (KaRen) study. Arch Cardiovasc Dis. 2014 Feb;107(2):112-21. doi: 10.1016/j.acvd.2013.11.002. Epub 2013 Dec 30. PMID: 24388161. https://doi.org/10.1016/j.acvd.2013.11.002

33. Brouwers FP, de Boer RA, van der Harst $P$, et al. Incidence and epidemiology of new onset heart failure with preserved vs. reduced ejection fraction in a community-based cohort: 11-year follow-up of PREVEND. Eur Heart J. 2013 May;34(19):1424-31. doi: 10.1093/eurheartj/eht066. Epub 2013 Mar 6. PMID: 23470495. https://doi.org/10.1093/eurheartj/eht066

34. Douglas PS, Katz SE, Weinberg EO, et al. Hypertrophic remodeling: gender differences in the 
early response to left ventricular pressure overload. J Am Coll Cardiol. 1998 Oct;32(4):1118-25. doi: 10.1016/s0735-1097(98)00347-7. PMID: 9768741. https://doi.org/10.1016/S0735-1097(98)00347-7

35. Kapoor JR, Heidenreich PA. Obesity and survival in patients with heart failure and preserved systolic function: a U-shaped relationship. Am Heart J. 2010 Jan;159(1):75-80. doi: 10.1016/j.ahj.2009.10.026. PMID: 20102870.

https://doi.org/10.1016/j.ahj.2009.10.026

36. Abohammar S, EISaidy MA, Fathalla D, Aldosarri M. Baseline characteristics of patients with heart failure and preserved ejection fraction at admission with acute heart failure in Saudi Arabia. Egypt Heart J. 2017 Mar;69(1):21-28. doi: 10.1016/j.ehj.2016.08.002. Epub 2016 Sep 3. PMID: 29622951; PMCID: PMC5839361.

https://doi.org/10.1016/j.ehj.2016.08.002

37. Tribouilloy C, Rusinaru D, Mahjoub $\mathrm{H}$, et al. Prognosis of heart failure with preserved ejection fraction: a 5 year prospective population-based study. Eur Heart J. 2008 Feb;29(3):339-47. doi: 10.1093/eurheartj/ehm554. Epub 2007 Dec 22. PMID: 18156618. https://doi.org/10.1093/eurheartj/ehm554

38. Adamo L, Perry A, Novak E, et al. Abnormal Global Longitudinal Strain Predicts Future Deterioration of Left Ventricular Function in Heart Failure Patients With a Recovered Left Ventricular Ejection Fraction. Circ Heart Fail. 2017 Jun;10(6):e003788. doi: 10.1161/CIRCHEARTFAILURE.116.003788. PMID: 28559418; PMCID: PMC5505492. https://doi.org/10.1161/CIRCHEARTFAILURE.116.00 3788

39. Unger ED, Dubin RF, Deo R, et al. Association of chronic kidney disease with abnormal cardiac mechanics and adverse outcomes in patients with heart failure and preserved ejection fraction. Eur $J$ Heart Fail. 2016 Jan;18(1):103-12. doi: 10.1002/ejhf.445. Epub 2015 Dec 3. PMID: 26635076 ; PMCID:

PMC4713321.

https://doi.org/10.1002/ejhf.445

40. Diao KY, Yang ZG, Ma M, et al. The Diagnostic Value of Global Longitudinal Strain (GLS) on Myocardial Infarction Size by Echocardiography: A Systematic Review and Meta-analysis. Sci Rep. 2017 Aug 30;7(1):10082. doi: 10.1038/s41598-017-090962. PMID: 28855658; PMCID: PMC5577208. https://doi.org/10.1038/s41598-017-09096-2 